\title{
Numerical Study of Flow and Heat Transfer in a Curved Square Duct with Longitudinal Triangular Rib Using A1203/Water Nanofluid
}

\author{
By Fatih Celen* \\ Omer Evran ${ }^{\dagger}$ \\ Oguz Turgut \\ Burak Tigli
}

Flow and heat transfer characteristics in curved ducts are different from that of straight ducts. A numerical study of a steady and three dimensional laminar flow in a 180 o curved square duct with longitudinal isosceles triangular rib has been conducted to investigate the effects of rib height, Dean number and volume fraction of Al2O3/water nanofluid on flow and heat transfer characteristics. ANSYS Fluent 17.0 commercial program is used for numerical simulation. Study is implemented for six Dean numbers changing from 250 to 1500, three different rib heights, and eight volume fractions varying from $0 \%$ to $5 \%$. Velocity and temperature regions, heat transfer coefficient $(h)$, pressure loss $(\square P)$, and thermal performance factor $(\square)$ are investigated. Present results are compared with the literature results. It is seen that present results are in good agreement with the results of literature. Results show that Dean number (De), rib height $(H)$ and volume fraction of nanofluid (vof) affect the heat transfer coefficient and pressure drop. It is seen that heat transfer coefficient may be increased by $59.0 \%$ for water as the working fluid when longitudinal isosceles triangular rib is used in curved square duct compared to ribless duct. Heat transfer coefficient may also be augmented by $30.8 \%$ using nanofluid as the working fluid in a curved square duct with rib. Results show that using longitudinal isosceles triangular rib in a curved square duct is advantageous.

Keywords: Curved, Nanofluid, Numerical study, Rib, Square duct.

\section{Nomenclature}

$a \quad$ edge length of the curved square duct, $\mathrm{m}$

$b \quad$ length of side wall of isosceles triangle, $\mathrm{m}$

$c_{\mathrm{p}} \quad$ specific heat at constant pressure, $\mathrm{J} \cdot \mathrm{kg}^{-1} \cdot \mathrm{K}^{-1}$

$D_{\mathrm{h}} \quad$ hydraulic diameter, $\mathrm{m}$

De Dean number, -

$f \quad$ Darcy friction factor, -

$h \quad$ heat transfer coefficient, $\mathrm{W} \cdot \mathrm{m}^{-2} \cdot \mathrm{K}^{-1}$

$H$ rib height, $\mathrm{m}$

\footnotetext{
*Gazi University, Turkey.

${ }^{\dagger}$ Gazi University, Turkey.

"Professor, Gazi University, Turkey.

•Gazi University, Turkey.
} 
$k \quad$ thermal conductivity, $\mathrm{W} \cdot \mathrm{m}^{-1} \cdot \mathrm{K}^{-1}$

$L \quad$ duct length, $\mathrm{m}$

$\mathrm{Nu} \quad$ Nusselt number, -

$\Delta p \quad$ pressure drop along the duct, $\mathrm{Pa}$

$\dot{q}^{\prime \prime} \quad$ heat flux, $\mathrm{W} \cdot \mathrm{m}^{-2}$

$P \quad$ pressure, $\mathrm{Pa}$

Pr Prandtl number, -

$R \quad$ curvature radius, $\mathrm{m}$

Re Reynolds number, -

$T$ temperature, $\mathrm{K}$

$u, v, w$ velocity components in $\mathrm{x}, \mathrm{y}, \mathrm{z}$ directions, $\mathrm{m} \cdot \mathrm{s}^{-1}$

$V \quad$ velocity, $\mathrm{m} \cdot \mathrm{s}^{-1}$

vof volume fraction, -

$\mathrm{x}, \mathrm{y}, \mathrm{z}$ coordinates, $\mathrm{m}$

\section{Greek Letters}

$\eta \quad$ thermal efficiency, -

$\mu \quad$ dynamic viscosity, $\mathrm{kg} \cdot \mathrm{m}^{-1} \cdot \mathrm{s}^{-1}$

$\theta \quad$ curvature angle, ${ }^{\circ}$

$\rho \quad$ density, $\mathrm{kg} \cdot \mathrm{m}^{-3}$

\section{Subscript}

bf base fluid

i inlet

$\mathrm{m}$ mean

nf nanofluid

o ribless duct

$\mathrm{p}$ particle

w wall

\section{Introduction}

Flows in curved ducts are different in nature from the flows in straight ducts. Flow with curvature is encountered in many engineering applications. Curved ducts with various cross sections are employed in many industrial devices such as internal combustion heat engine passages, rocket engines, solar collectors, turbomachinery, heat exchangers, chemical reactors, internal cooling system of gas turbines, centrifugal pumps, and air conditioning and refrigeration systems (Silva et al., 1999; Papadopoulos and Hatzikonstantinou, 2004; Ko, 2006; Liang et al., 2013; Ojha and Joshi, 2014).

In order to increase heat transfer rates, nanoparticles such as $\mathrm{Al}_{2} \mathrm{O}_{3}, \mathrm{TiO}_{2}$, $\mathrm{SiO}_{2}, \mathrm{CuO}, \mathrm{Fe}_{2} \mathrm{O}_{3}, \mathrm{Fe}_{3} \mathrm{O}_{4}$ and so on are added to the basefluid such as water, 
ethylene glycol, oil and others. To augment heat transfer, fins are also used on the surfaces of the ducts.

Many researchers have investigated the laminar flow in a curved square duct with or without nanofluid as the working fluid. A numerical study was carried out by Cheng et al. (1975) in thermal entrance region of a curved square duct for different fluids $(\operatorname{Pr}=0.1,0.7,5,10.05$ and 500) and Dean numbers changing from 0 to 488 at both constant surface temperature and constant heat flux boundary conditions. The ratio of the radius of curvature to the height of a duct, i.e. curvature ratio $R / a$, was taken as $4-100$, and curvature angle was not given accurately. They proposed a correlation which gives the Nusselt number. Humphrey et al. (1977) conducted both an experimental and numerical study of laminar flow in a $90^{\circ}$ bend square duct $(40 \mathrm{~mm} \times 40 \mathrm{~mm})$ with the mean radius of $92 \mathrm{~mm}$ and radius ratio, the ratio of mean radius to the edge length of the duct $R / a$, of 2.3 using water as the working fluid for the Dean number of 368 . Corresponding Reynolds number is 416 . Yee et al. (1980) numerically studied the heat transfer for steady and laminar flow through a $90^{\circ}$ curved square duct. They investigated the effects of duct geometry and entrance conditions which are velocity and temperature on heat transfer. Chilukuri and Humphrey (1981) numerically studied the incompressible laminar flow in a $90^{\circ}$ curved square duct using finite difference method. They considered the buoyancy effects in their numerical study. Hille et al. (1985) experimentally investigated the development of laminar flow in a $180^{\circ}$ curved square duct with a curvature ratio of 6.45. Laser Doppler Anenometry measurements were conducted. Soh (1988) presented a numerical study of developing laminar flow in a $180^{\circ}$ curved square duct using alternating direction implicit (ADI) finite difference method for the curvature ratios $a / R$, the ratio of the edge length of the duct (hydraulic diameter of the duct) to the curvature radius, of $1 / 6.45$ and $1 / 2.3$. Numerical study was investigated for two different Reynolds numbers 574 and 790. Hwang and Chao (1991) studied numerically the laminar forced convection through an isothermal curved square duct under both thermally and hydrodynamically fully developed boundary conditions. They performed their numerical study for two different fluids ( $\operatorname{Pr}=0.7$ and 7), and Dean number was varied between 0 and $10^{6}$. An experimental and numerical study was conducted by Bara et al. (1992) for fully developed, incompressible, laminar and Newtonian fluid in a smooth curved square duct for the curvature ratio of 15.1. Dean numbers used were 125, 137 and 150. Chung and Hyun (1992) numerically investigated the developing laminar flow in a $90^{\circ}$ curved square duct for both constant temperature and constant heat flux boundary conditions. Mees et al. (1996) conducted an experimental and numerical study of the incompressible, steady, and developing laminar flow for Newtonian fluid in a $270^{\circ}$ curved square duct with the curvature ratio, the ratio of the radius of the curvature to the edge length of of the duct $R / a$, of 15.1 for Dean number changing from 200 to 600 . Radius of the curvature $R$ was taken as $19.17 \mathrm{~cm}$. Silva et al. (1999) studied numerically the incompressible, steady and fully developed laminar flow in curved elliptic or rectangular ducts for the aspect ratio varying between 0.7 and 1.4 for constant wall temperature boundary condition. Dean number was varied between 30 and 
400. Papadopoulos and Hatzikonstantinou (2004) numerically examined the steady and fully developed laminar flow in a curved square duct with internal longitudinal fins using SIMPLE algorithm. Papadopoulos and Hatzikonstantinou (2005) numerically examined the incompressible and fully developed laminar flow in a curved square duct with four internal longitudinal fins using alternating direction implicit method (ADI). Tsai and Sheu (2007) studied the incompressible three dimensional laminar flow in a $90^{\circ}$ curved square duct with curvature ratio, i.e. the ratio of curvature radius to the edge length of duct, of 2.3 for Reynolds number of 790. Kucuk and Asan (2009) numerically examined the steady, incompressible and both thermally and hydrodynamically fully developed laminar flow in eccentric annular curved square duct. Air was used as the working fluid ( $\operatorname{Pr}=0.7)$. Mondal et al. (2009) numerically investigated the flow instability through a curved square duct. Kucuk (2010) presented a numerical study of the entropy generation for steady, incompressible thermally and hydrodynamically fully developed laminar flow in concentric annular curved square duct for the annulus dimension ratios of 2.36, 2.9, 3.8 and 5.5. Numerical study was conducted for the Dean numbers varying from 3.6 to 207 . Onur et al. (2011) carried out a numerical study to investigate the steady, three dimensional laminar flow in a $180^{\circ}$ curved square duct for air at constant wall temperature boundary condition. Dean number was changed between 165 and 1450. Corresponding Reynolds number is between 250 and 2200. Sasmito et al. (2011) numerically investigated the laminar heat transfer enhancement in coiled square tubes for water- $\mathrm{Al}_{2} \mathrm{O}_{3}$ and water-CuO nanofluids.Entropy generation for temperature variable viscosity in a laminar flow in a curved square microchannel was numerically examined by Guo et al. (2012) for constant wall temperature boundary condition. Shabestari et al. (2012)numerically studied the isothermal, incompressible, steady and fully developed laminar flow in a curved square duct. Soltanipour et al. (2012) carried out a numerical study in a curved square duct with longitudinal rectangular rib on the inner surface of the outer wall of the curved duct for laminar flow. Study was conducted for three dimensional, steady and incompressible laminar flow. $\mathrm{Al}_{2} \mathrm{O}_{3}$ /water nanofluid was used as the working fluid. Almeida Vilela (2013) conducted a numerical and experimental study of fully developed laminar flow inside a $180^{\circ}$ curved square duct. Heris et al. (2013) conducted an experimental study of laminar convective heat transfer using $\mathrm{Al}_{2} \mathrm{O}_{3}$ /water nanofluid in a curved square duct. Islam and Mondal (2013) numerically examined the study of fully developed, incompressible and two dimensional laminar flow in a curved square duct for the Dean number changing from 0 to 6000. Numerical study was carried out for the curvature 0.001 to 0.5 . Liang et al. (2013) carried out a numerical study for unsteady, incompressible, fully developed, and three dimensional laminar flow in a $90^{\circ}$ curved circular and square duct. Vilela (2013) both experimentally and numerically investigated three dimensional laminar flow in a $180^{\circ}$ curved square duct using finite volume method for the Dean number varying from 100 to 2500. Ma et al. (2014) conducted a numerical study to investigate the laminar and turbulent flows for non-Newtonian fluidin a curved square duct. Ojha and Joshi (2014) numerically investigated the steady three dimensional laminar flow in a $120^{\circ}$ and $160^{\circ}$ curved 
square ducts with the curvature ratio of 2.3. Air was used as the working fluid in their study. Numerical study was conducted for four different Reynolds numbers 227, 455, 1061, and 2274 (corresponding Dean number 150, 300, 700, and 1500). Farsani and Nodooshan (2015) numerically investigated the laminar flow and heat transfer in $90^{\circ}$ curved square duct using nanofluid of aluminum oxide and water $\left(\mathrm{Al}_{2} \mathrm{O}_{3}\right)$. Razavi et al. (2015) carried out a numerical study to investigate the second law analysis of laminar forced convection in a rotating $180^{\circ}$ curved square duct. Helal et al. (2016) conducted a numerical study to investigate the two dimensional laminar flow and heat transfer through a $180^{\circ}$ rotating curved square duct. Liu et al (2018) numerically investigated the laminar forced convective heat transfer in developing and fully developed regions of a curved square duct using $\mathrm{Al}_{2} \mathrm{O}_{3}$-water nanofluids.

Heat transfer and fluid flow in curved non-square ducts for laminar flow have also been investigated using nanofluids by many investigators (Chen and Zhang, 2003; Nobari and Gharali, 2006; Akbarinia and Behzadmehr, 2007; Akbarinia, 2008; Nobari et al., 2009; Nobari and Mehrabani, 2010; Yang et al., 2011; Nobari et al., 2012; Kahani et al., 2014; Hayat et al., 2016; Ahmed and Akbar, 2017; Barik and Nayak, 2017).

Literature survey shows that there is a lack of knowledge on the topic of laminar flow in a curved square duct with rib for nanofluids. Therefore, in this study, a numerical analysis of steady, incompressible three dimensional laminar flow in a curved square duct with longitudinal isosceles triangular rib has been carried out using $\mathrm{Al}_{2} \mathrm{O}_{3}$ /water nanofluid. The novelty of this study is the investigation of laminar flow and heat transfer characteristics in a $180^{\circ}$ curved square duct with longitudinal isosceles triangular rib placed on the inner surface of the outer wall for $\mathrm{Al}_{2} \mathrm{O}_{3}$ /water nanofluid. Examined parameters are the rib height, the Dean number and the volume fraction of nanofluid. Rib heights used in this study are $H=0.112 a, 0.189 a$, and 0.283 a, i.e. $b / a=1.5 / 10,2.14 / 10,3 / 10$. Dean number is varied between 250 and 1500 . Corresponding Reynolds number is between 338 and 2122. The volume fraction of nanofluid is changed from $0 \%$ to $5 \%$.

\section{Description of the Physical Problem}

The curved square duct with longitudinal isosceles triangular rib and coordinate system used in this numerical study are shown in Figure 1. Isosceles triangular sectioned rib is placed longitudinally on the inner surface of the outer wall of the curved square duct. Constant heat flux is applied to the outside of the outer wall of the curved square duct. Other surfaces of the curved duct are insulated. In Figure $1, a, b$, and $R$ are the edge length of the square curved duct, length of side wall of isosceles triangle, and the curvature radius, respectively. The values of $a$ and $R$ are taken as $56 \mathrm{~mm}$ and $99 \mathrm{~mm}$, respectively. $\theta$ is the curvature angle or streamwise length, measured from inlet section. $\theta=0^{\circ}$ and $\theta=90^{\circ}$ designate the inlet and outlet sections, respectively. Base length and height of the triangular rib are taken as $0.20 a$ and $H$, respectively. That is, 
length of side wall of isosceles triangular rib, $b$, is chosen as $0.15 a 0.214 a$ and $0.30 a$. Therefore, numerical study has been carried out for three different rib heights $H=0.112 a, 0.189 a, 0.283 a$, for six different Dean numbers De=250, $500,750,1000,1250,1500$, and for eight different volume fractions of nanofluid $v o f=0,0.1,0.2,0.5,1,2.5,4,5 \%$.

Figure 1. Duct Geometry and Coordinate System
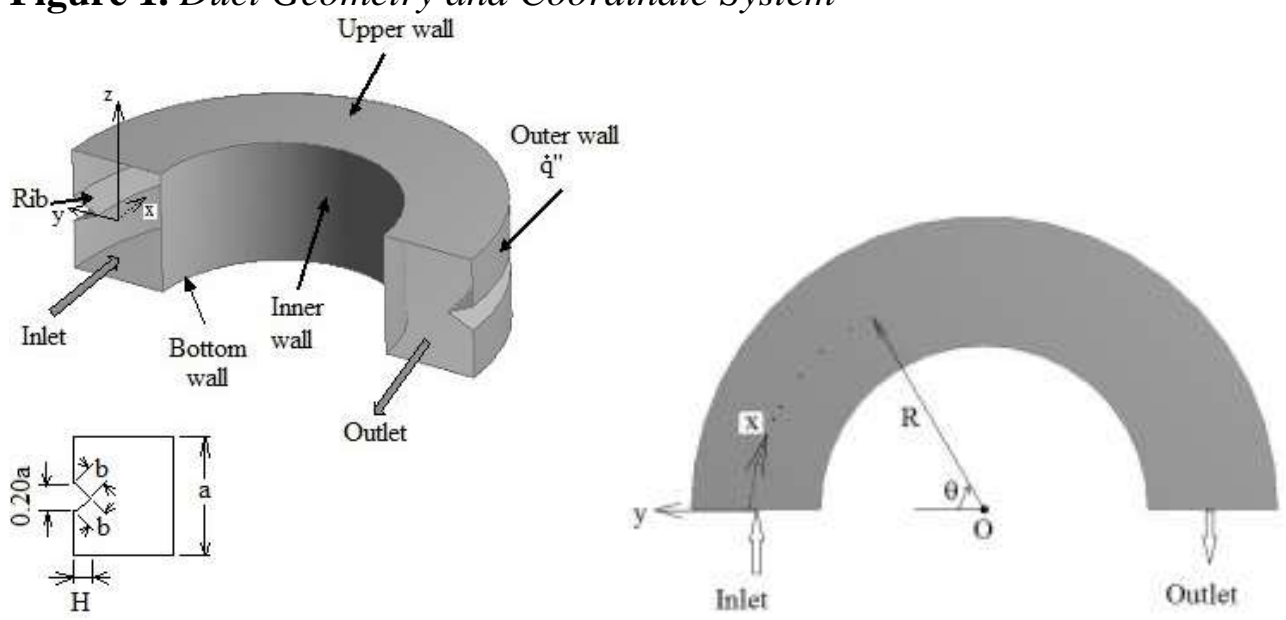

Steady, three dimensional, viscous incompressible laminar flow with negligible buoyancy effects are assumed for this numerical study. Radiative transport and viscous dissipation are considered to be negligibly small and dropped from the energy equation. Physical properties of the fluid are assumed to be constant. Therefore, with these assumptions the equations of continuity and momentum equations for flow in $180^{\circ}$ curved square duct are (WardSmith, 1980).

Conservation of mass:

$\frac{\mathrm{R}}{\mathrm{R}+\mathrm{y}} \frac{\partial \mathrm{u}}{\partial \mathrm{x}}+\frac{\partial \mathrm{v}}{\partial \mathrm{y}}+\frac{\partial \mathrm{w}}{\partial \mathrm{z}}+\frac{\mathrm{v}}{\mathrm{R}+\mathrm{y}}=0$

Conservation of momentum:

$$
\begin{array}{r}
\frac{R}{R+y} u \frac{\partial u}{\partial x}+v \frac{\partial u}{\partial y}+w \frac{\partial u}{\partial z}+\frac{u v}{R+y}=\frac{1}{\rho}\left[\frac{R}{R+y}\left(-\frac{\partial P}{\partial x}\right)+\mu\left\{\left(\frac{R}{R+y}\right)^{2} \frac{\partial^{2} u}{\partial x^{2}}+\frac{\partial^{2} u}{\partial y^{2}}+\frac{\partial^{2} u}{\partial z^{2}}\right.\right. \\
\left.\left.+\frac{1}{R+y} \frac{\partial u}{\partial y}+\frac{2 R}{(R+y)^{2}} \frac{\partial v}{\partial x}-\frac{u}{(R+y)^{2}}\right\}\right]
\end{array}
$$




$$
\begin{aligned}
\frac{R}{R+y} u \frac{\partial v}{\partial x}+v \frac{\partial v}{\partial y}+w \frac{\partial v}{\partial z}-\frac{u^{2}}{R+y}=\frac{1}{\rho}\left[-\frac{\partial P}{\partial y}+\mu\left\{\left(\frac{R}{R+y}\right)^{2} \frac{\partial^{2} v}{\partial x^{2}}+\frac{\partial^{2} v}{\partial y^{2}}+\frac{\partial^{2} v}{\partial z^{2}}\right.\right. \\
\left.\left.+\frac{1}{R+y}\left[\frac{\partial v}{\partial y}-\frac{2 R}{R+y} \frac{\partial u}{\partial x}-\frac{v}{R+y}\right]\right\}\right]
\end{aligned}
$$

$\frac{\mathrm{R}}{\mathrm{R}+\mathrm{y}} \mathrm{u} \frac{\partial \mathrm{w}}{\partial \mathrm{x}}+\mathrm{v} \frac{\partial \mathrm{w}}{\partial \mathrm{y}}+\mathrm{w} \frac{\partial \mathrm{w}}{\partial \mathrm{z}}=\frac{1}{\rho}\left[-\frac{\partial \mathrm{P}}{\partial \mathrm{z}}+\mu\left\{\left(\frac{\mathrm{R}}{\mathrm{R}+\mathrm{y}}\right)^{2} \frac{\partial^{2} \mathrm{w}}{\partial \mathrm{x}^{2}}+\frac{\partial^{2} \mathrm{w}}{\partial \mathrm{y}^{2}}+\frac{\partial^{2} \mathrm{w}}{\partial \mathrm{z}^{2}}+\frac{1}{\mathrm{R}+\mathrm{y}} \frac{\partial \mathrm{w}}{\partial \mathrm{y}}\right\}\right]_{(2 \mathrm{c})}$

and conservation of energy equation is (Hwang and Chao, 1991)

$$
\frac{\mathrm{R}}{\mathrm{R}+\mathrm{y}} \mathrm{u} \frac{\partial \mathrm{T}}{\partial \mathrm{x}}+\mathrm{v} \frac{\partial \mathrm{T}}{\partial \mathrm{y}}+\mathrm{w} \frac{\partial \mathrm{T}}{\partial \mathrm{z}}=\frac{\mathrm{k}}{\rho \mathrm{c}_{\mathrm{p}}}\left[\left(\frac{\mathrm{R}}{\mathrm{R}+\mathrm{y}}\right)^{2} \frac{\partial^{2} \mathrm{~T}}{\partial \mathrm{x}^{2}}+\frac{\partial^{2} \mathrm{~T}}{\partial \mathrm{y}^{2}}+\frac{\partial^{2} \mathrm{~T}}{\partial \mathrm{z}^{2}}+\frac{1}{\mathrm{R}+\mathrm{y}} \frac{\partial \mathrm{T}}{\partial \mathrm{y}}\right] \text { (3) }
$$

where $\rho$ is the density, $P$ is the pressure, $\mu$ is the dynamic viscosity, $c_{\mathrm{p}}$ is the specific heat at constant pressure, $k$ is the thermal conductivity, and $T$ is the temperature.

Fluid enters the curved square duct with uniform velocity $V_{\mathrm{i}}$ and temperature $T_{\mathrm{i}}$ at $\theta=0^{\circ}$. Alternatively, fully developed velocity profiles can be applied at the duct inlet depending on the desired type of inlet boundary conditions (Darus and Fatt, 2008). No slip boundary conditions are applied to the walls of the curved duct and rib. Constant heat flux boundary condition is applied to the outer wall of the duct. Adiabatic boundary condition is applied to the bottom, inner and top walls of the curved square duct.

The length of the side edge of the isosceles triangular rib changes as the height of the isosceles triangular rib changes. In order to see the effect of the rib height on flow and heat transfer, the heated surface area is kept at constant. Therefore, it is assumed that the surfaces of rib are adiabatic. Atmospheric boundary condition is applied to the outlet section, i.e. at $\theta=180^{\circ}$. Fluid properties are assumed to be constant and taken at the inlet temperature.

Reynolds (Re) and Dean (De) numbers are expressed, respectively, as (Soltanipour et al., 2012).

$$
\begin{aligned}
& \operatorname{Re}=\rho V_{\mathrm{i}} D_{\mathrm{h}} / \mu \\
& \operatorname{De}=\operatorname{Re}\left(D_{\mathrm{h}} / R\right)^{0.5}
\end{aligned}
$$

In Eqs. (4) and (5), $\rho$ is the density, $V_{\mathrm{i}}$ is the inlet velocity of the fluid to the curved square duct, $D_{\mathrm{h}}$ is the hydraulic diameter of the curved square duct and defined as four times the wetted area to the perimeter, $\mu$ is the dynamic viscosity, and $R$ is the curvature radius. Dean number changes from 250 to 1500 (corresponding Reynolds number is between 338 and 2122). Average heat transfer coefficient in the curved square duct is defined as 
Vol. 5, No. 2 Celen et al.: Numerical Study of Flow and Heat Transfer in a Curved...

$$
h=\dot{q}^{\prime \prime} /\left(T_{\mathrm{w}}-T_{\mathrm{m}}\right)
$$

where $h$ is the heat transfer coefficient, $\dot{q}^{\prime \prime}$ is the heat flux applied to the outer wall of the curved square duct, $T_{\mathrm{w}}$ is the wall temperature, and $T_{\mathrm{m}}$ is the bulk temperature of the fluid. Average Darcy friction (f) factor and average Nusselt number $(\mathrm{Nu})$ are given, respectively, as

$$
\begin{aligned}
& \mathrm{f}=2(\Delta P / L)\left(D_{\mathrm{h}} / \rho V_{\mathrm{i}}^{2}\right) \\
& \mathrm{Nu}=h D_{\mathrm{h}} / k
\end{aligned}
$$

where $\Delta P$ is the pressure drop along the curved square duct, $L$ is the duct length, and $k$ is the thermal conductivity of the fluid, respectively. Thermal efficiency is defined as

$$
\eta=\left(\mathrm{Nu} / \mathrm{Nu}_{\mathrm{o}}\right) /\left(\mathrm{f} / \mathrm{f}_{\mathrm{o}}\right)^{1 / 3}
$$

here $\mathrm{Nu}_{\mathrm{o}}$ and $\mathrm{f}_{\mathrm{o}}$ are the Nusselt number and Darcy friction factor for the ribless duct, respectively.

\section{Thermophysical Properties of the $\mathrm{Al}_{2} \mathrm{O}_{3}$ /Water Nanofluid}

Water is used as base fluid. $\mathrm{Al}_{2} \mathrm{O}_{3}$ is employed as the nanoparticles in base fluid. The volume fraction of particle in nanofluid is changed from $0 \%$ to $5 \%$. Single phase model is assumed, and the following equations are used to compute the density $\rho$, dynamic viscosity $\mu$, specific heat at constant pressure $c_{\mathrm{p}}$, and thermal conductivity $k$ of the $\mathrm{Al}_{2} \mathrm{O}_{3}$ /water nanofluid (Soltanipour et al., 2012):

$$
\begin{aligned}
& \rho_{\mathrm{nf}}=(1-v o f) \rho_{\mathrm{bf}}+v o f \cdot \rho_{\mathrm{p}} \\
& \mu_{\mathrm{nf}}=\mu_{\mathrm{bf}}\left(123 \cdot v o f^{2}+7.3 \cdot v o f+1\right) \\
& c_{\mathrm{p}, \mathrm{nf}}=(1-v o f) c_{\mathrm{p}, \mathrm{bf}}+v o f \cdot c_{\mathrm{p}}, \mathrm{p} \\
& k_{\mathrm{nf}}=k_{\mathrm{bf}}\left(4.97 \cdot v o f^{2}+2.72 \cdot v o f+1\right)
\end{aligned}
$$

where the subscripts nf, bf and $\mathrm{p}$ indicate the nanofluid, the base fluid, and the particle, respectively.

\section{Meshing and Numerical Solution Procedure}

Numerical study is carried out using commercial program ANSYS Fluent 17.0. ANSYS Fluent 17.0 uses the control volume analysis to solve fluid flow problems. Nonuniform tetrahedral meshes with inflation near the walls are used in the numerical study. Figure 2 shows the typical mesh distribution on three 
dimensional geometry. Typical mesh distribution on the cross section of the square duct with triangular rib is also seen in Figure 2. As can be seen in Figure 2, a dense mesh distribution is used near the walls of the curved square duct and near the walls of the triangular rib. Mesh independence study for Dean number $\mathrm{De}=1500$ which is the highest Dean number used in this numerical study is conducted to reduce the influence of the number of meshes on the computational results. The mesh number for which average Nusselt number and average Darcy friction factor in curved square duct does not change significantly is taken as the optimum mesh number. This optimum mesh number is used for other Dean numbers in the numerical analysis at the same duct geometry. Similarly, mesh optimization is carried out when the duct geometry and the volume fraction of nanofluid are changed. No convergence problem is encountered in numerical studies. Steady segregated solver is used. The standard SIMPLE-algorithm is employed for pressure-velocity coupling. The second order upwind scheme is chosen for the convective terms. Iterations are continued until the residual falls below $10^{-5}$ for mass and momentum equations while energy equation is iterated until the residual falls below $10^{-6}$.

Figure 2. The View of a Typical Mesh used in this Numerical Study

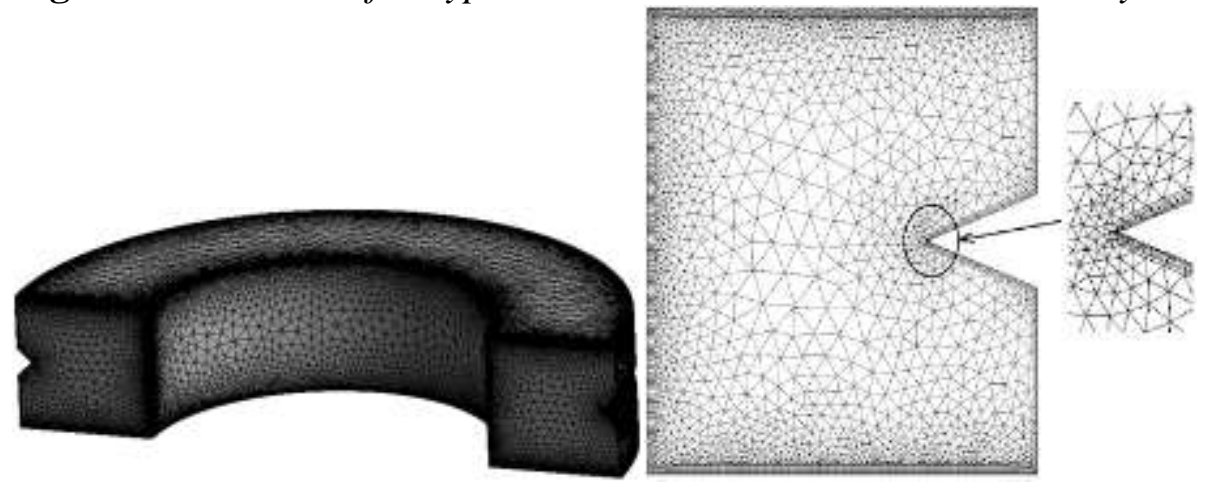

\section{Results and Discussion}

\section{Verification of Numerical Study}

The numerical study of Soltanipour et al. (2012) was repeated here to ensure the accuracy of the present numerical study. Numerical study was carried out for $180^{\circ}$ curved square duct with a longitudinal isosceles triangular rib placed on the inner surface of the outer wall of the curved duct. The ratio of the rib height to the side length of the duct $H / a$ is equal to $1 / 5$. Dean number used was chosen to be $\mathrm{De}=500$ and $\mathrm{De}=1500$, and the volume fraction of nanofluid was taken as $v o f=2.5 \%, 5 \%, 7.5 \%$, and $10 \%$. Figure 3 shows the comparison of the present results with the results of Soltanipour et al. (2012). As can be seen in Figure 3a and $3 b$, the heat transfer coefficient and pressure drop ratios of the ribbed curved duct to the smooth (ribless) curved square duct are plotted as a function of the volume fraction of the nanofluid. In Figure 3, the subscripts nfr and bfs designate 
the nanofluid for curved ribbed duct and base fluid for smooth curved duct, respectively. It is seen that the results of present study are in good agreement with the results of Soltanipour et al. (2012). Validation can be carried out by conducting an experimental study as well.

In order to see the effects of nanofluids on friction factor, friction factor for pressure loss given in Figure $3 \mathrm{~b}$ for $\mathrm{De}=1500$ and $\mathrm{De}=500$ is plotted in Figure $3 \mathrm{c}$ as a function of the volume fraction of nanofluid. As can be seen from Figure $3 \mathrm{c}$, friction factor increases with increasing volume fraction of nanofluid at constant Dean number. It is also seen that friction factor decreases with increasing Dean number at constant volume fraction of nanofluid. It is found that friction factor for $\mathrm{De}=500$ and $\mathrm{De}=1500$ at $v o f=10 \%$ increases by $1047 \%$ and $906 \%$, respectively, when compared with curved duct for $v o f=0 \%$ (i.e. without nanofluid).

Figure 3. Comparison of Heat Transfer Coefficient (a) and Pressure Drop (b); Friction Factor vs. Volume Fraction of Nanofluid (c)

(a)

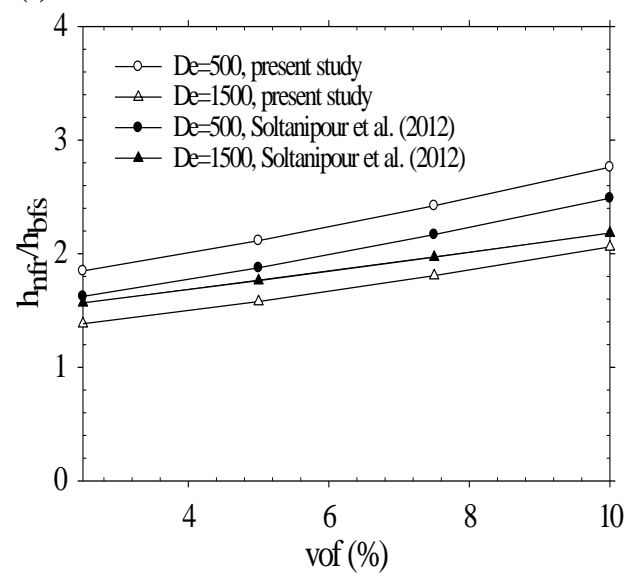

(c)

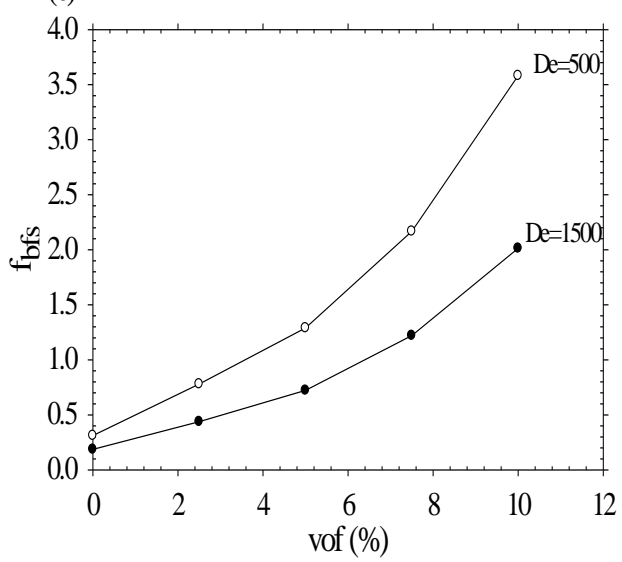

(b)

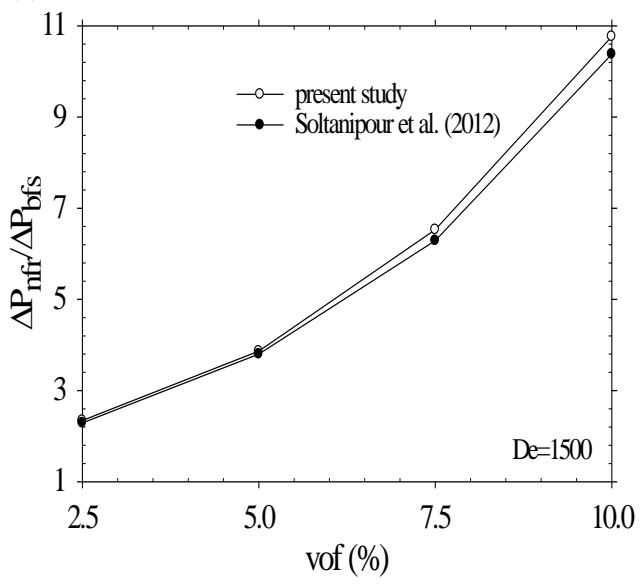




\section{Results of Curved Duct With Longitudinal Isosceles Triangular Rib}

After verifying the numerical method used in this study, the numerical study of laminar flow in a curved square duct with a longitudinal isosceles triangular rib placed on the inner surface of the outer wall of the curved square duct has been carried out. The parameters used are the Dean number (De), the height of the isoseceles triangular rib $(H)$, and the volume fraction of nanofluid (vof). Dean numbers used are 250, 500, 750, 1000, 1250, and 1500. Three different rib height is used, i.e. $H=0.112 a, 0.189 a$, and $0.283 a$. Numerical study has been implemented for eight volume fractions of nanofluid $v o f=0,0.1,0.2$, $0.5,1,2.5,4,5 \%$.

Velocity and temperature contours for water, i.e. vof $=0 \%$, are seen in Figure 4 for $\mathrm{De}=250$ at three different rib heights $H=0.112 a, 0.189 a$, and $0.283 a$ from left to right, respectively. In Figure 4, velocity and temperature contours are seen from top to bottom, respectively. As can be seen in Figure 4, rib height affects the velocity and temperature fields in duct. It is seen that flow becomes symmetric with respect to the plane $\mathrm{z}=0$. It is also seen that velocity magnitude changes from minimum value near the wall due to no slip boundary condition to maximum value for fluid near the middle of the cross section of the duct. It is seen that important temperature rise happens in a thin region close to the outer wall which is exposed to the external heat flux. It is also seen that higher temperature regions are coincident with the low velocity regions near the outer wall. As seen from Figure 4, more fluid region is heated near the outer surface as the rib height increases. Warming of the fluid in the larger region results in higher heat transfer.

Figure 4. Typical Velocity and Temperature Contours for Water at De=250. From Top to Bottom: Velocity and Temperature Contours, Respectively

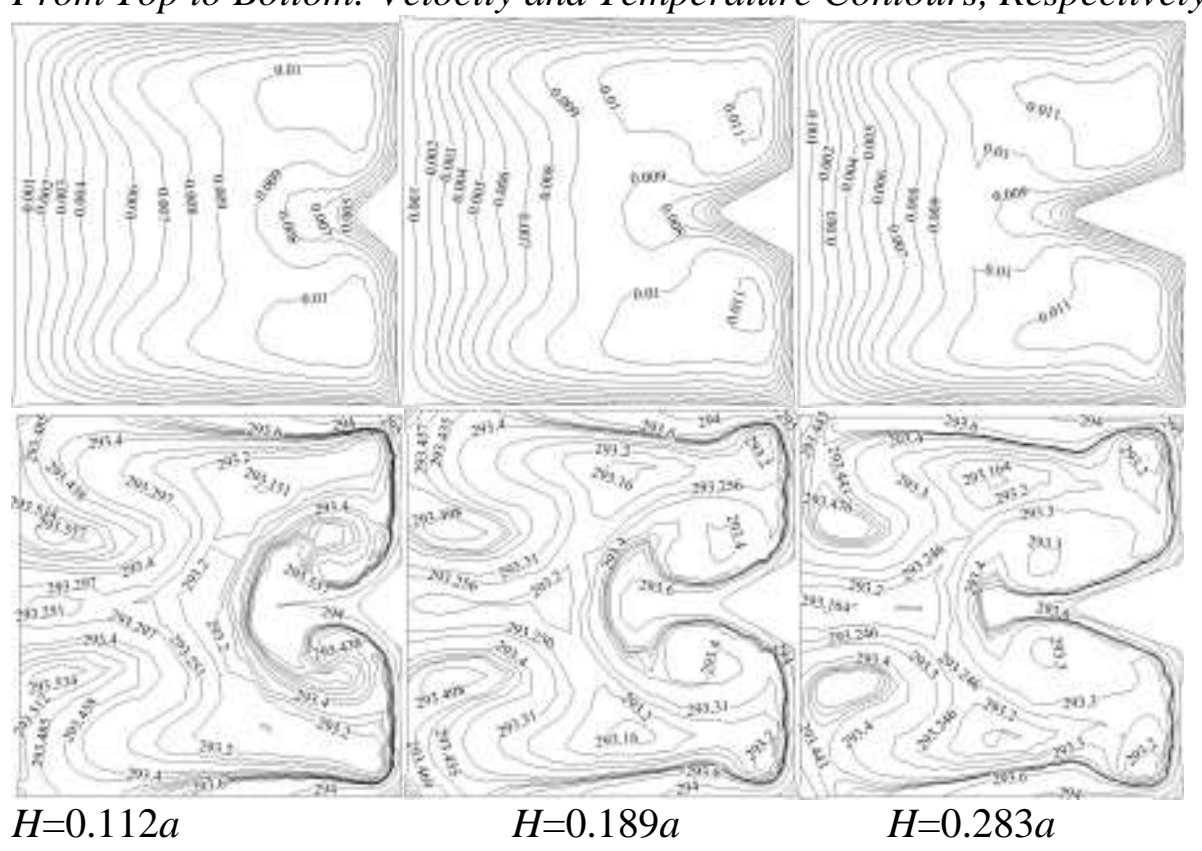


In order to see the effect of the Dean number on velocity and temperature fields, typical velocity and temperature contours are plotted in Figure 5 at three different Dean numbers $D e=250,500$ and 750 for $H=0.283 a$ and volume fraction of $v o f=1 \%$. From top to bottom, velocity and temperature contours, respectively, are seen in Figure 5. As can be seen in Figure 5, Dean number affects the velocity and temperature fields in the duct. Results show that velocity magnitude increases with increasing Dean number as expected, but temperature magnitude of fluid decreases.

Figure 5. Typical Velocity and Temperature Contours at vof $=1 \%$ for $H=0.283 a$. From Top to Bottom: Velocity and Temperature Contours, Respectively

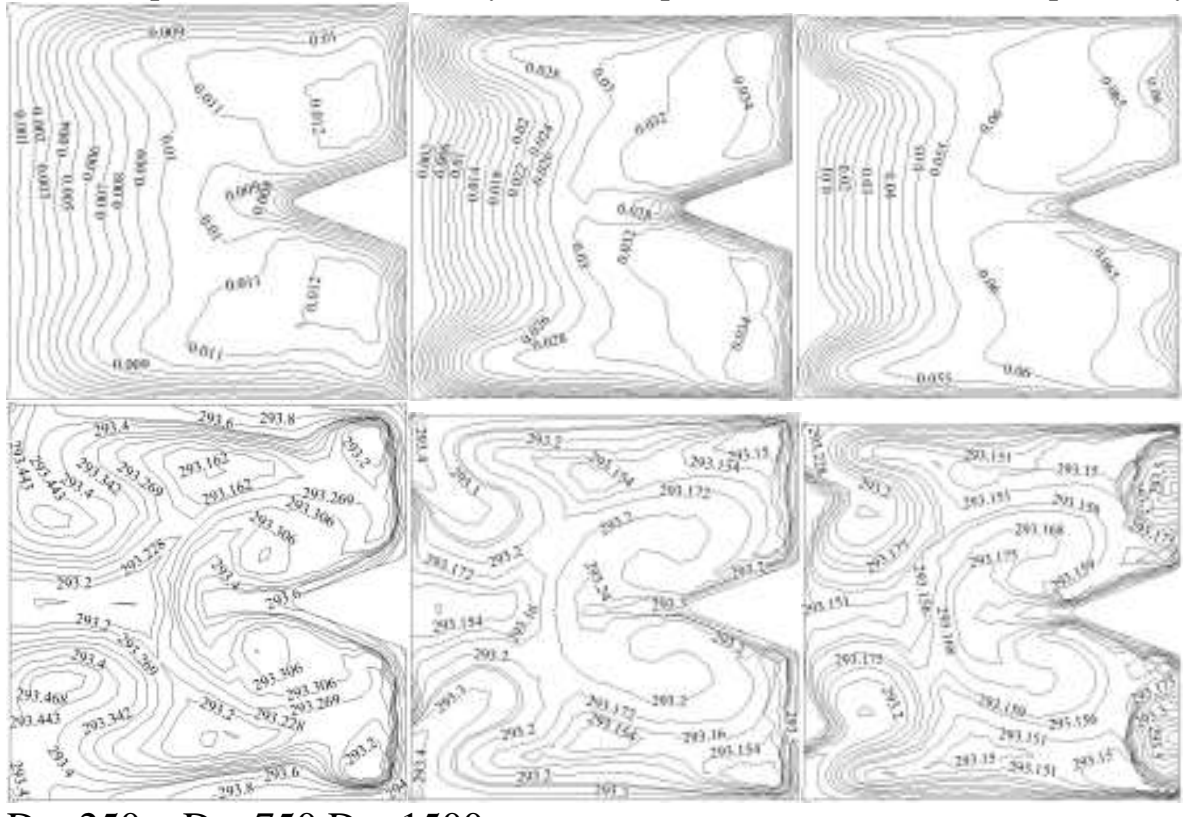

$\mathrm{De}=250 \quad \mathrm{De}=750 \mathrm{De}=1500$

Typical velocity and temperature contours for $\mathrm{De}=250$ and $H=0.283 a$ are shown in Figure 6 in order to see the effect of the volume fraction of nanofluid on velocity and temperature fields. It is seen that the volume fraction of nanofluid affects the velocity and temperature regions.

Typical velocity and temperature contours are shown in Figure 7 at $\theta=90^{\circ}$ and $\theta=180^{\circ}$ (outlet section), respectively, for $H=0.283 a$ and $D e=250$ at $v o f=1 \%$. It is seen that velocity and temperature boundary layers grow in the flow direction. In other words, more fluid is heated when the fluid flows in the axial direction. It is seen that the high velocity zone transfers from the inner side to the outer side as the flow develops from inlet plane to the outlet plane due to the influence of centrifugal force. 
Figure 6. Typical Velocity and Temperature Contours at De $=250$ for $H=0.283 a$. From Top to Bottom: Velocity and Temperature Contours, Respectively

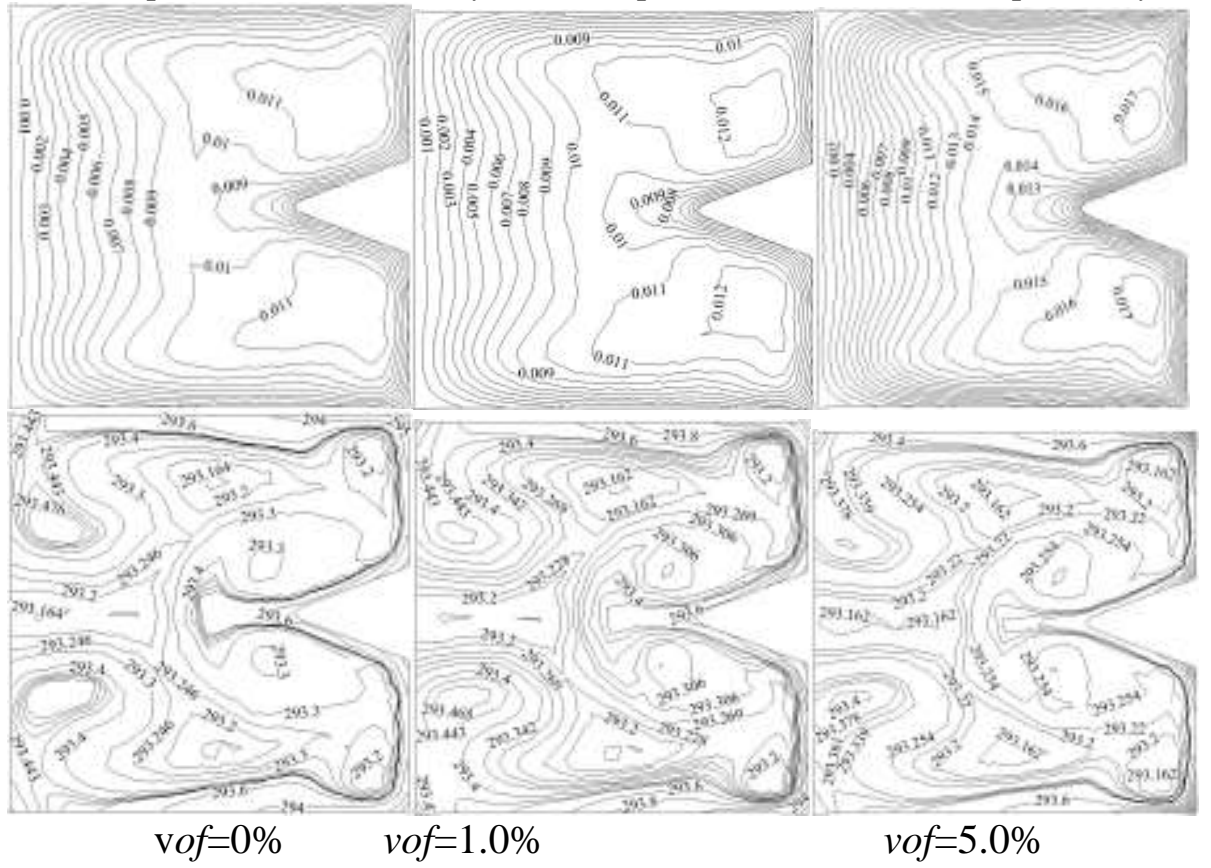

Figure 7. Typical Velocity and Temperature Contours at De $=250$ for $H=0.283 a$ and $\theta=90^{\circ}$ and $\theta=180^{\circ}$. From Top to Bottom: Velocity and Temperature Contours, Respectively

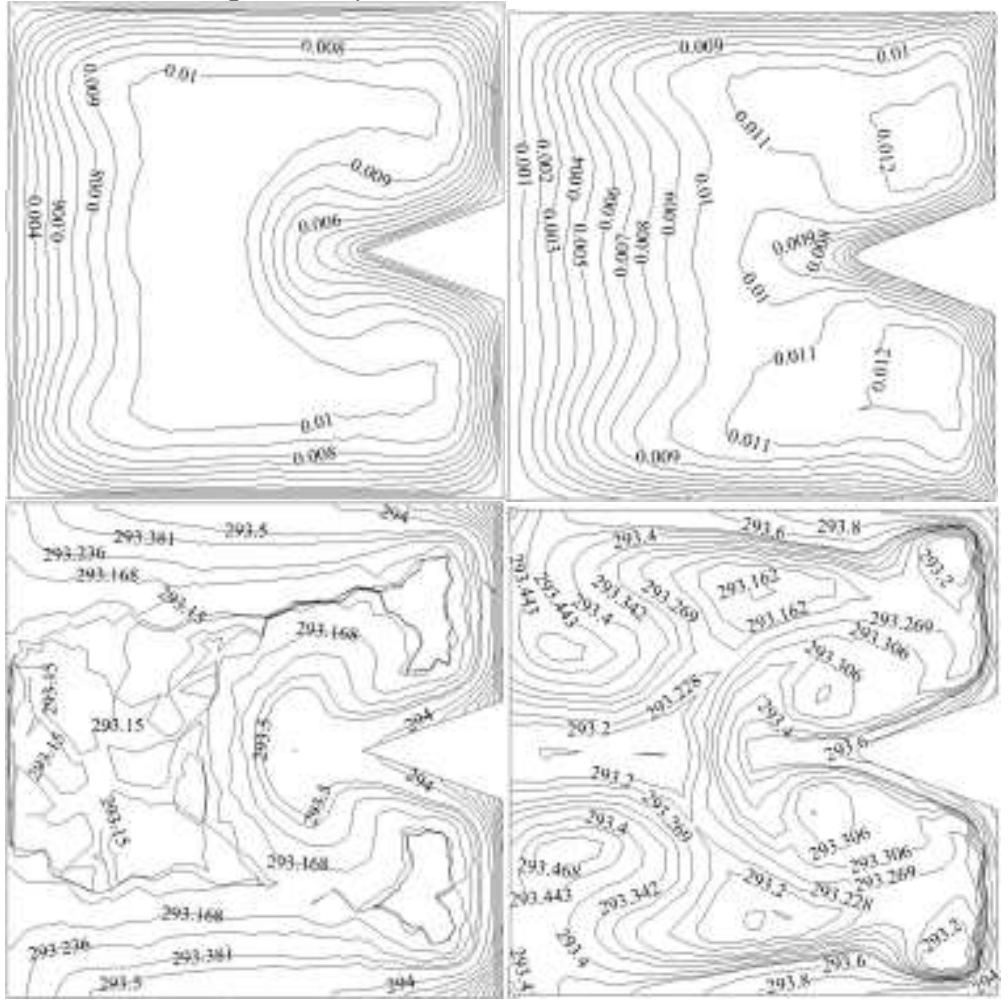

$\theta=90^{\circ} \theta=180^{\circ}$ 
The effect of the volume fraction of nanofluid (vof) and Dean number (De) on heat transfer coefficient is shown in Figure 8 at two different rib heights $H=0.112 a$ and $H=0.283 a$, respectively. As can be seen in Figure 8, heat transfer coefficient increases when the volume fraction of nanofluid increases at a constant Dean number. It is also seen that heat transfer coefficient increases when Dean number increases at a constant volume fraction of nanofluid. That is, the volume fraction of nanofluid and Dean number have an important factor on the heat transfer coefficient in $180^{\circ}$ curved square duct with isosceles triangular rib on the inner surface of the outer wall of curved duct. It is seen that heat transfer coefficient for $H=0.112 a$ and $H=0.283 a$ increases about $30 \%$ and $31 \%$, respectively, for $\mathrm{De}=1500$ and $v o f=5 \%$ when compared with $v o f=0 \%$ (ie. without nanofluid). Likewise, heat transfer coefficient for $\mathrm{De}=250$ and $\mathrm{De}=1500$ increases about $29 \%$ and $31 \%$, respectively, for $H=0.283 a$ and $v o f=5 \%$ when compared with $v o f=0 \%$ (i.e. without nanofluid).

Figure 8. Heat Transfer Coefficient as a Function of Volume Fraction at Different Dean Numbers
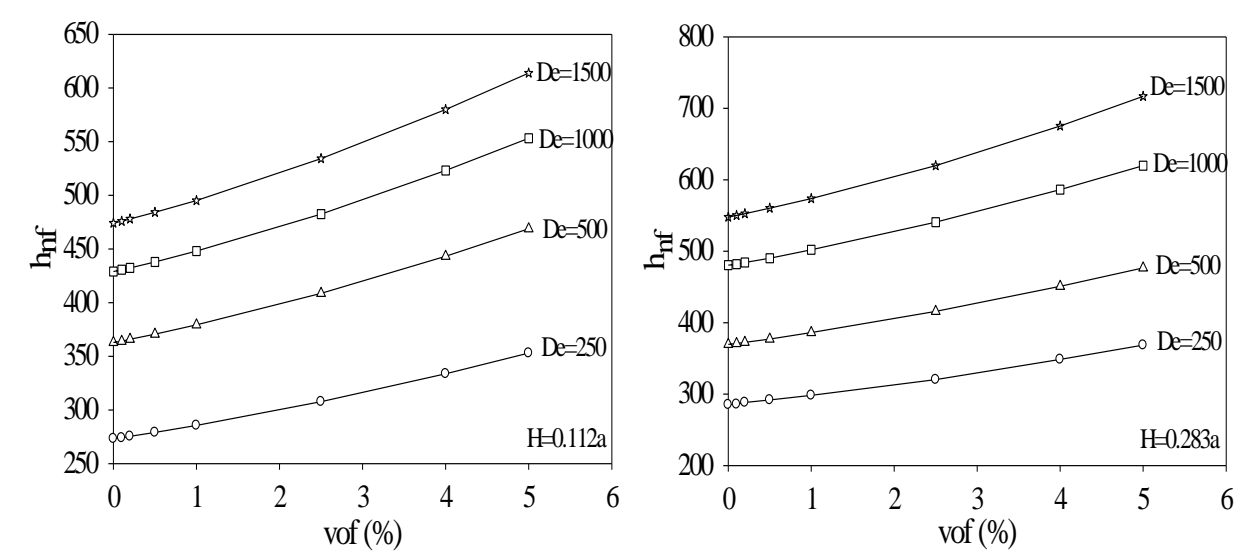

In order to see the effect of triangular rib height on heat transfer coefficient, heat transfer coefficient is plotted as a function of the volume fraction of nanofluid in Figure 9 at three different rib heights for two different Dean numbers. It is seen that heat transfer coefficient increases when rib height increases at a constant volume fraction of nanofluid. In other words, rib height affects the heat transfer coefficient. It is also seen that heat transfer coefficient increases with increasing volume fraction of nanofluid at a constant rib height. That is, volume fraction of nanofluid influences heat transfer coefficient. It is seen that heat transfer coefficient for $H=0.112 a$ and $H=0.283 a$ increases by $29.2 \%$ and $29 \%$, respectively, for $\mathrm{De}=1500$ and $v o f=5 \%$ when compared with $v o f=0 \%$ (i.e. without nanofluid).

Likewise, the effect of volume fraction of nanofluid and Dean number on pressure drop is shown in Figure 10 at two different rib heights $H=0.112 a$ and $0.283 a$, respectively. It is seen that pressure drop increases when volume fraction of nanofluid increases at a constant Dean number. In addition, pressure drop in the curved ribbed-square duct increases when Dean number increases at a 
constant volume fraction of nanofluid. That is, volume fraction of nanofluid and Dean number affect the pressure drop in a curved ribbed-square duct. It is seen that pressure drop for $H=0.112 a$ and $H=0.283 a$ increases by $144 \%$ and $145 \%$, respectively, for $\mathrm{De}=1500$ and $v o f=5 \%$ when compared with $v o f=0 \%$ (i.e. without nanofluid).

Figure 9. Heat Transfer Coefficient as a Function of Volume Fraction of Nanofluid at Different $H$ Values
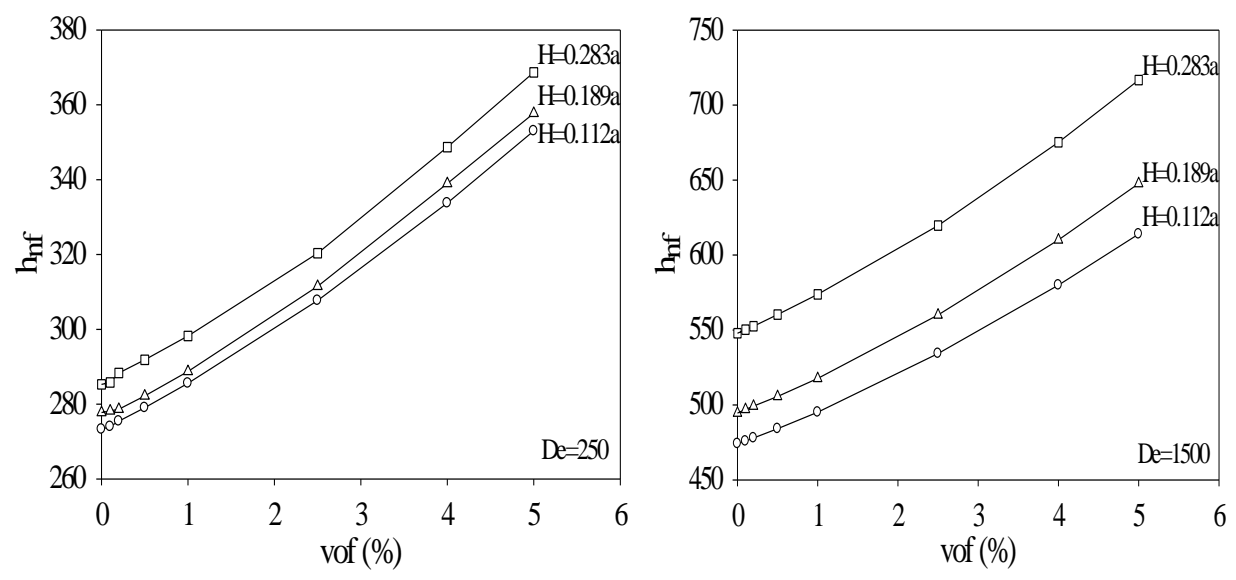

Figure 10. Pressure Drop as a Function of Volume Fraction at Different Dean Numbers
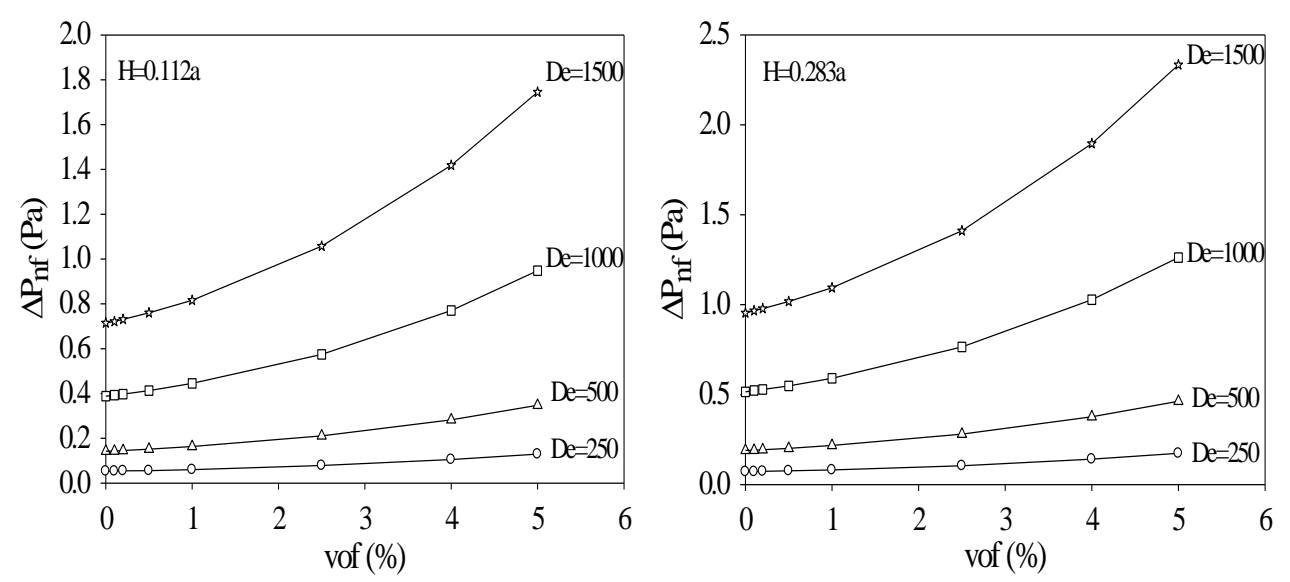

To see the effect of rib height on pressure drop, pressure drop along the curved ribbed-square duct is plotted as a function of volume fraction of nanofluid in Figure 11 at three different rib heights and at two different Dean numbers $\mathrm{De}=250$ and 1500, respectively. Results show that rib height affects the pressure drop in the curved duct. That is, pressure drop in the curved duct increases when rib height increases at a constant volume fraction of nanofluid for both Dean numbers. It is also seen that pressure drop increases when volume fraction of nanofluid increases at constant rib height for two Dean numbers. It is seen that pressure drop for $\mathrm{De}=250$ and $\mathrm{De}=1500$ increases by $144 \%$ and $145 \%$, 
Vol. 5, No. 2 Celen et al.: Numerical Study of Flow and Heat Transfer in a Curved...

respectively, for $H=0.283 a$ and $v o f=5 \%$ when compared with $v o f=0 \%$ (i.e. without nanofluid).

Figure 11. Pressure Drop as a Function of Volume Fraction of Nanofluid at Different $H$ Values
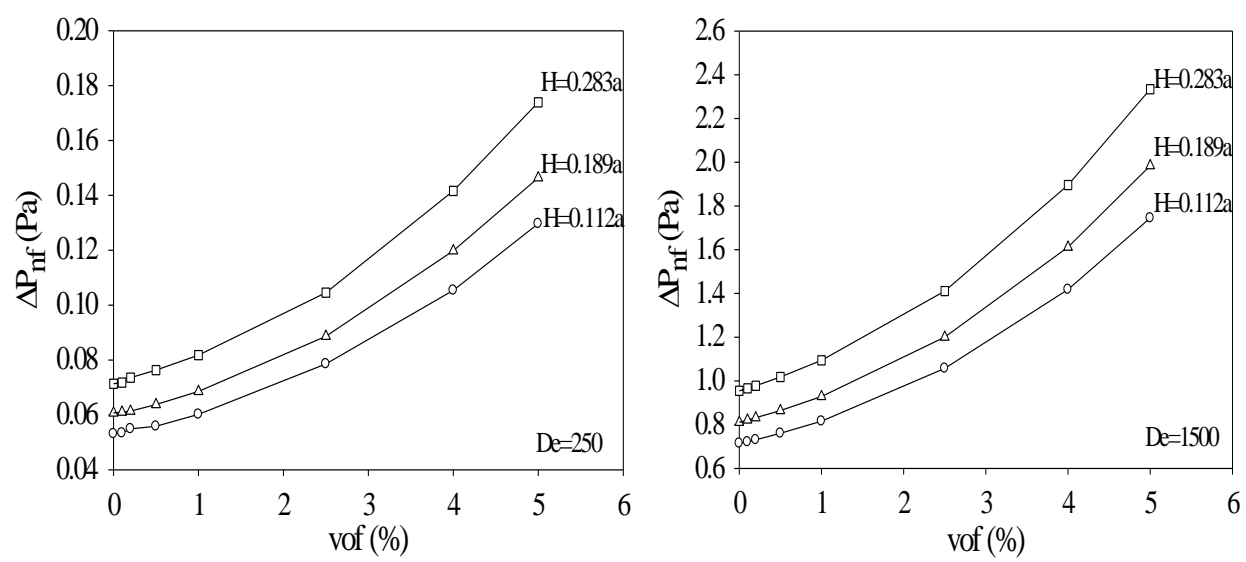

Heat transfer and pressure drop values for two Dean numbers De $=250$ and 1500 are given in Table 1 for curved smooth (ribless) duct and for curved ribbed duct for which $H=0.283 a$ at two volume fractions of nanofluid, $v o f=0 \%$ and 5\%. Results show that both heat transfer and pressure drop increases when a longitudinal isosceles triangular rib is placed on the inner surface of the outer wall of the curved square duct. It is also seen that heat transfer coefficient increases with increasing Dean number.

Table 1. Heat Transfer and Pressure Drop Values for $H=0.283 a$

\begin{tabular}{|c|c|c|c|c|c|c|}
\hline \multirow{2}{*}{ De } & \multirow{2}{*}{$\begin{array}{c}h_{\mathrm{bfs}} \\
(v o f=0 \%)\end{array}$} & \multicolumn{2}{|c|}{$h_{\text {nfr }}$} & \multirow{2}{*}{$\begin{array}{c}\Delta P_{\mathrm{bfs}} \\
(v o f=0 \%)\end{array}$} & \multicolumn{2}{|c|}{$\Delta P_{\mathrm{nfr}}$} \\
\hline & & $v o f=0 \%$ & $v o f=5 \%$ & & $v o f=0 \%$ & $v o f=5 \%$ \\
\hline 250 & 179.47 & 285.29 & 368.66 & 0.0443 & 0.0714 & 0.1739 \\
\hline 1500 & 465.19 & 547.80 & 716.69 & 0.6441 & 0.9546 & 2.3340 \\
\hline
\end{tabular}

Firstly, attention will be given to the heat transfer coefficient. Results show that heat transfer coefficient increases by $59.0 \%$ and $17.8 \%$ for $\mathrm{De}=250$ and 1500 , respectively, at $v o f=0 \%$ when longitudinal isosceles triangular rib with $H=0.283 a$ is used in curved square duct compared to ribless duct. It is also seen that heat transfer coefficient for curved ribbed-square duct increases by $29.2 \%$ and $30.8 \%$ for $\mathrm{De}=250$ and 1500 , respectively, at $H=0.283 a$ when the volume fraction of nanofluid changes from $0 \%$ to $5 \%$. In other words, heat transfer coefficient increases by $105.4 \%$ and $54.1 \%$ for $\mathrm{De}=250$ and 1500 , respectively, when rib with $H=0.283 a$ and nanofluid with $v o f=5 \%$ are used in a curved duct compared to curved ribless duct.

With regard to pressure drop, pressure drop increases by $61.2 \%$ and $48.2 \%$ for $\mathrm{De}=250$ and 1500 , respectively, at the volume fraction of nanofluid $v o f=0 \%$ 
when longitudinal rib with $H=0.283 a$ is used in curved square duct compared to ribless duct. In addition, pressure drop increases by $143.6 \%$ and $144.5 \%$ for $\mathrm{De}=250$ and 1500 , respectively, for the rib height $H=0.283 a$ when volume fraction of nanofluid changes from $v o f=0 \%$ to $5 \%$ for curved ribbed-square duct. That is, pressure drop increases by $262.4 \%$ when isosceles triangular rib with $H=0.283 a$ and nanofluid with $v o f=5 \%$ are used in a curved square duct compared to curved ribless duct.

Increasing of heat transfer is advantageous while increasing of pressure drop is a disadvantageous. In order to see that whether using a longitudinal isosceles triangular rib in a curved square duct is reasonable or not, thermal efficiency is plotted as a function of volume fraction of nanofluid in Figure 12 at four different Dean numbers for three different rib heights. Results indicate that thermal efficiency is greater than unity at all rib heights and at all Dean numbers. In other words, it can be said that heat transfer dominates the friction factor at all Dean numbers and at all rib heights.

Figure 13 shows the thermal efficiency as a function of volume fraction of nanofluid at three rib heights $H=0.112 a, 0.189 a$, and $0.283 a$ for three different Dean numbers $D e=250,500$ and 1500 . It is seen that thermal efficieny is greater than unity for all cases. That is, heat transfer dominates the friction. Therefore, it can be said that using a longitudinal isosceles triangular rib on the inner surface of the outer wall of curved square duct is reasonable.

Figure 12. Thermal Efficiency Versus Volume Fraction of Nanofluid at Three Different Rib Heights
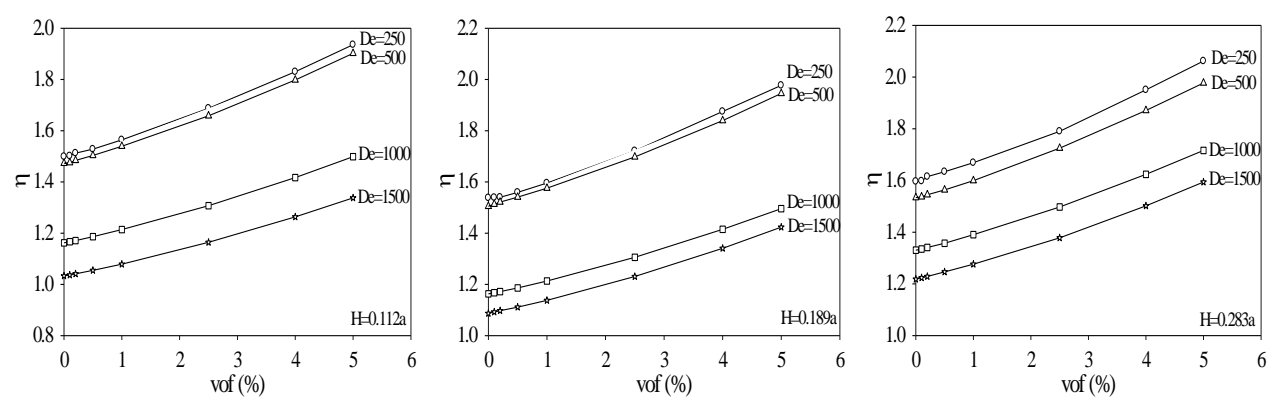

Figure 13. Thermal Efficiency Versus Volume Fraction of Nanofluid at Three Different Dean Numbers
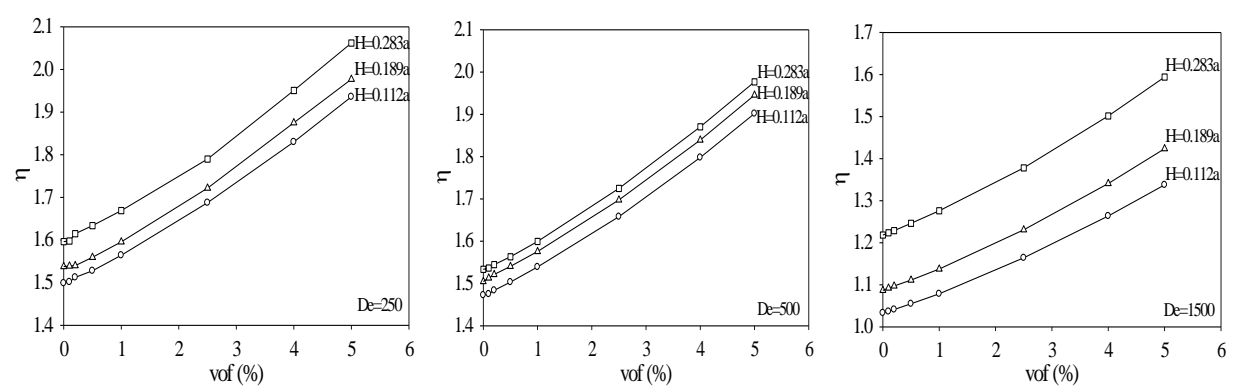


\section{Conclusions}

The novelty of this study is the numerical investigation of laminar flow and heat transfer characteristics in a $180^{\circ}$ curved square duct with longitudinal isosceles triangular rib placed on the inner surface of the outer wall for $\mathrm{Al}_{2} \mathrm{O}_{3}$ / water nanofluid. Parameters examined in this study are the Dean number, the volume fraction of nanofluid, and the rib heights. A commercial program called ANSYS Fluent 17.0 is used in the numerical analysis. The principle conclusions are as follows for $\mathrm{De}=250-1500, v o f=0 \%-5 \%$ and $H=0.112 a, 0.189 a$, and $0.283 \mathrm{a}$ :

(1) Results show that heat transfer coefficient and pressure drop increase when the volume fraction of nanofluid, Dean number and rib height increase.

(2) Results show that heat transfer coefficient increases by $59 \%$ for water as the working fluid ( $v o f=0 \%$ ) when longitudinal isosceles triangular rib is used on the inner surface of the outer wall of a $180^{\circ}$ curved square duct compared to ribless duct.

(3) Heat transfer coefficient may be increased $105 \%$ when using nanofluid in a $180^{\circ}$ curved square duct with longitudinal isosceles triangular ribwhen compared to curved ribless duct.

(4) Heat transfer coefficient may also be augmented about $31 \%$ using nanofluid in a $180^{\circ}$ curved square duct with longitudinal isosceles triangular ribwhen compared with the water without nanofluid.

(5) Pressure drop increases by $61 \%$ when a longitudinal isosceles triangular rib is used on the inner surface of the outer wall of $180^{\circ}$ curved square duct compared to curved ribless duct when water is used as the working flud, i.e. $v o f=0 \%$.

(6) Pressure drop increases by $145 \%$ using nanofluid in a $180^{\circ}$ curved square duct with longitudinal isosceles triangular ribwhen compared with $v o f=0 \%$ (i.e. without nanofluid).

(7) Pressure drop increases by $262 \%$ using nanofluid when a longitudinal isosceles triangular rib is used on the inner surface of the outer wall of $180^{\circ}$ curved square duct compared to curved ribless duct.

(8) It can be said that using a longitudinal isosceles triangular rib on the inner surface of outer wall of the curved square duct is reasonable.

\section{References}

Ahmed, F. and Akbar, N. S. 2017. Heat transfer analysis of CNT suspended nanofluid through annulus sector duct. Int. J. Mech. Sci. 122, 362-369. DOI= https://doi. org/10.1016/j.ijmecsci.2017.01.017.

Akbarinia, A. and Behzadmehr, A. 2007. Numerical study of laminar mixed convection of a nanofluid in a horizontal curved tubes. Appl. Therm. Eng. 27, 8-9, 327-337. DOI= https://doi.org/10.1016/j.applthermaleng.2006.10.034.

Akbarinia A. 2008. Impacts of nanofluid flow on skin friction factor and Nusselt number in curved tubes with constant mass flow. Int. J. Heat Fluid Flow, 29, 1, 229-241. DOI= https://doi.org/10.1016/j.ijheatfluidflow.2007.05.003. 
Almeida Vilela, C. A. 2013. Laminar flow inside square cross section $180^{\circ}$ curved duct: Numerical solutions and experimental visualization. 22nd Int. Cong. Mech. Eng. (COBEM 2013), p. 7307-7313, November 3-7, Brazil.

Bara, B., Nandakumar, K. and Masliyah, J. H. 1992. An experimental and numerical study of the Dean problem: flow development towards two-dimensional multiple solutions. J. Fluid Mech. 244, (Nov. 1992), 339-376. DOI=https://doi.org/10.10 17/S0022112092003100.

Barik, A. K. and Nayak, B. 2017. Fluid flow and heat transfer characteristics in a curved rectangular duct using Al2O3-water nanofluid. J. Heat Mass Transf. Res. DOI= https://doi.org/10.22075/JHMTR.2017.1689.1115, In Press.

Chen, H. and Zhang, B. 2003. Fluid flow and mixed convection heat transfer in a rotating curved pipe. Int. J. Therm. Sci. 42, 11, 1047-1049. DOI=https://doi.org/10.1016/ S1290-0729(03)00088-7.

Cheng, K. C., Lin, R. C., and Ou, J. W. 1975. Graetz problem in curved square channels. J. Heat Transf. 97, 2 (May 1975), 244-248. DOI= https://doi.org/10.1115/1.3450 348.

Chikukuri, R. and Humphrey, J. A. C. 1981. Numerical computation of buoyancyinduced recirculation in curved square duct laminar flow. Int. J. Heat Mass Tran. 24, 2 (Feb. 1981), 305-314. DOI=https://doi.org/10.1016/0017-9310(81)90038-7.

Chung, J. H. and Hyun, J. M. 1992. Convective heat transfer in the developing flow region of a square duct with strong curvature. Int. J. Heat Mass Tran. 35, 10 (Oct. 1992), 2537-2550. DOI=https://doi.org/10.1016/0017-9310(92) 90095-A.

Darus, A. N. and Fatt, Y. Y. 2008. Development of secondary flow in a curved rectangular duct. Jurnal Mekanikal, 27, 1-22.

Farsani, A. K. and Nodooshan, A. A. 2015. Numerical Investigation Of Nanofluids Flow and Heat Transfer in $90^{\circ}$ Elbow With square Cross-Section. Ciência eNatura $37,2,162-172$.

Guo, J., Xu, M., Tao, Y., and Huai, X. 2012. The effect of temperature-dependent viscosity on entropy generation in curved square microchannel. Chem. Eng. Process. 52, 85-91. DOI=https://doi.org/10.1016/j.cep.2011.11.008.

Hayat, T., Tanveera, A. and Alsaedib, A. 2016. Numerical analysis of partial slip on peristalsis of MHD Jeffery nanofluid in curved channel with porous space. $J$. Mol. Liq. 224, 944-953. DOI=https://doi.org/ 10.1016/j.molliq.2016.10.057.

Helal, Md. N. A., Ghosh, B. P. and Mondal, R. N. 2016. Numerical simulation of twodimensional laminar flow and heat transfer through a rotating curved square channel. Am. J. Fluid Dyn. 6, 1, 1-10. DOI=https://doi.org/10.5923/j.ajfd.20160601.01.

Heris, S. Z., Nassan, T. H., Noie, S. H., Sardarabadi, H., and Sardarabadi, M. 2013. Laminar convective heat transfer of $\mathrm{Al}_{2} \mathrm{O}_{3}$ /water nanofluid through square crosssectional duct. Int. J. Heat Fluid Fl. 44, (Dec. 2013), 375-382. DOI=https://doi. org/10.1016/j.ijheatfluidflow.2013.07.006.

Hille, P., Vehrenkamp, R., and Schulz-Dubois, E. O. 1985. The development and structure of primary and secondary flow in a curved square duct. J. Fl. Mech. 151, (Feb. 1985), 219-241.DOI=http://bit.ly/2Hct9Tm.

Humphrey, J. A. C., Taylor, A. M. K. and Whitelaw, J. H. 1977. Laminar flow in a square duct of strong curvature. $J$. Fl. Mech. 83, 3 (Dec. 1977), 509-527. DOI=https://doi. org/10.1017/S0022112077001311.

Hwang, G. J. and Chao, C. H. 1991. Forced laminar convection in a curved isothermal square duct. J. Heat Trans. 113, (Feb. 1991), 48-55. DOI=https://doi.org/10.1115/1. 2910550. 
Islam, M. S. and Mondal, R. N. 2013. Effects of curvature on unsteady solutions through a curved square duct flow. Procedia Eng. 56, 217-224. DOI=doi.org/10.1016/j.Pro eng.2013.03.110.

Kahani, M., Heris, S. Z. and Mousavi, S. M. 2014. Experimental investigation of TiO2/ water nanofluid laminar forced convective heat transfer through helical coiled tube. Heat Mass Transf. 50, 1563-1573. DOI=https://doi.org/10.1007/s00231-014-1367-4.

Ko, T. H. 2006. Numerical investigation on laminar forced convection and entropy generation in a curved rectangular duct with longitudinal ribs mounted on heated wall. Int. J. Therm. Sci. 45, 390-404. DOI=https://doi.org/10.1016/j.ijtthermalsci. 2005.06.005.

Kucuk, H. and Asan, H. 2009. Forced convection heat transfer in eccentric curved annular square ducts. J. Therm. Sci. Technol. 29, 1, 67-78.

Kucuk, H. 2010. Numerical analysis of entropy generation in concentric curved annular ducts. J. Mech. Sci. Technol. 24, 9, 1927-1937. DOI=https://doi.org/10.1007/s12 206-010-0629-4.

Liang, S. J., Jan, Y. J. and Huang, C. A. 2013. A quasi-implicit time-advancing scheme for flow in a three-dimensional curved duct. Numer. Heat Tr. B. 64, 306-325. DOI=https://doi.org/10.1080/10407790.2013.806203.

Liu, F., Cai, Y., Wang, L. and Zhao, J. 2018. Effects of nanoparticle shapes on laminar forced convective heat transfer in curved ducts using two-phase model. Int. J. Heat Mass Tran. 116, 292-305. DOI=http://bit.ly/2o2OtSN.

Ma, K., Yuan, S., Chang, H. and Lai, H. 2014. Experimental study of Pseudoplastic fluid flows in a square duct of strong curvature. J. Therm. Sci. 23, 4, 359-367. DOI=https://doi.org/10.1007/s11630-014-0718-2.

Mees, P. A. J., Nandakumar, K. and Masliyah, J. H. 1996. Instability and transitions of flow in a curved square duct: the development of two pairs of Dean vortices. $J$. Fl. Mech. 314, 227-246. DOI=http://bit.ly/2CihpLr.

Mondal, R. N., Islam, Md. S. and Hossain, S. Md. T. 2009. GANIT J. Bangladesh Math. Soc. 29 (2009), 71-85.

Nobari, M. R. H. and Gharali, K. 2006. A numerical study of flow and heat transfer in internally finned rotating straight pipes and stationary curved pipes. Int. J. Heat Mass Tran.49, 1185-1194. DOI=http://bit.ly/2EzwbTr.

Nobari, M. R. H. and Ahrabi, B. R. andAkbari, G. 2009. A numerical analysis of developing flow and heat transfer in a curved annular pipe. Int. J. Therm. Sci. 48, 8, 1542-1551. DOI=https://doi.org/10.1016/j.ijthermalsci.2008.12.004.

Nobari, M. R. H. and Mehrabani, M. T. 2010. A numerical study of fluid flow and heat transfer in eccentric curved annuli. Int. J. Therm. Sci. 49, 2, 380-396, DOI=https:// doi.org/10.1016/j.ijthermalsci.2009.07.003.

Nobari, M. R. H., Mirzaei, M. and Nik, Z. H. 2012. A numerical investigation of developing flow in an eccentric curved annulus in the presence of gravity. Int. J. Nonlinear Mech. 47, 4, 108-117, DOI=http://bit.ly/2BXfC2Q.

Ojha, R. K. and Joshi, P. V. 2014. Numerical analysis of forced convection and heat transfer in curved duct. Int. J. Recent Trends Mech. Eng. 2, 4 (June 2014).

Onur, N., Turgut, O. and Arslan, K. 2011. Three-dimensional numerical analysis of forced convection flow and heat transfer in a curved square duct. J. Therm. Sci. Technol. 31, 2, 13-24.

Papadopoulos, P. K. and Hatzikonstantinou, P. M. 2004. Numerical analysis of fully developed flow in curved square ducts with internal fins. J. Fluid Eng.-T. ASME. 126, 752-757. DOI=https://doi.org/10.1115/1.1792269. 
Papadopoulos, P. K. and Hatzikonstantinou, P. M. 2005. Thermally developing flow in curved square ducts with internal fins. Heat Mass Trans. 42, 30-38. DOI=https:// doi.org/10.1007/s00231-004-0572-y.

Razavi, S. E., Soltanipour, H. and Choupani, P. 2015. Second law analysis of laminar forced convection in a rotating curved duct. Therm Sci. 19, 1, 95-107. DOI=https:// doi.org/10.2298/TSCI120606034R.

Sasmito, A. P., Kurnia, J. C. and Mujumdar, A. S. 2011. Numerical evaluation of laminar heat transfer enhancement in nanofluid flow in coiled square tubes. Nanoscale Res. Lett. 6, 1, 376 (1-14). DOI=https//doi.org/10.1186/1556-276X-6-376.

Shabestari, A. S., Sadeghy, K. and Raisee, M. 2012. On the use of lattice Boltzmann model for simulating dean flow of non-Newtonian fluids in curved square ducts. Commun. Nonlinear Sci. Numer. Simulat. 17, 4250-5261. DOI=https://doi.org/10.10 16/j.cnsns.2012.03.026.

Silva, R. J., Valle, R. M. and Ziviani, M. 1999. Numerical hydrodynamic and thermal analysis of laminar flow in curved elliptic and rectangular ducts. Int. J. Therm. Sci. 38, 585-594.

Soh, W. Y. 1988. Developing fluid flow in curved duct of square cross-section and its fully developed dual solutions. J. Fl. Mech. 188, 337-361. DOI=https://doi.org/ 10.1017/S0022112088000758.

Soltanipour, H., Choupani, P. and Mirzaee, I. 2012. Numerical analysis of heat transfer enhancement with the use of $\gamma-\mathrm{Al}_{2} \mathrm{O}_{3} /$ water nanofluid and longitudinal ribs in a curved duct. Therm. Sci. 16, 2, 469-480. DOI=https://doi.org/10.2298/TSCI110719 028S.

Tsai, S. F. and Sheu, T. W. H. 2007. Numerical exploration of flow topology and vortex stability in a curved duct. Int. J. Numer. Meth. Eng. 71, 564-582. DOI=https://doi. org/10.1002/nme.1959.

Vilela, C. A. de A. 2013. Laminar flow inside square cross section $180^{\circ}$ curved duct: numerical solutions and experimental visualization. $22^{\text {nd }}$ Int. Congress Mech. Eng. (Nov. 2013), 7307-7313.

Ward-Simith, A. J. 1980. Internal Fluid Flow: The Fluid Dynamics of Flow in Pipes and Ducts, pp. 250-251, Clarendon Press, Oxford.

Yang, J., Cheng, D., Di, Q., Zhu, J. and Zhang, J. 2011. Effect of elbows on stability of water-based $\mathrm{TiO} 2$ nanofluids under laminar flow conditions. Proceedings of the ASME 2011 Power Conference, p. 1-8, July 12-14, Colorado, USA.

Yee, G., Chilukuri, R. and Humphrey, J. A. C. 1980. Developing flow and heat transfer in strongly curved ducts of rectangular cross section. J. Heat Transf. 102, 2 (May 1980), 285-291. DOI=https://doi.org/10.1115/1.3244275. 
